\title{
Diagnostic performance of fractional excretion of urea in the evaluation of critically ill patients with acute kidney injury: a multicenter cohort study
}

Michael Darmon ${ }^{1,2,3^{*}}$, Francois Vincent ${ }^{4}$, Jean Dellamonica ${ }^{2,5}$, Frederique Schortgen ${ }^{6}$, Frederic Gonzalez ${ }^{4}$, Vincent Das ${ }^{7}$, Fabrice Zeni ${ }^{1,3}$, Laurent Brochard ${ }^{2,8}$, Gilles Bernardin ${ }^{5}$, Yves Cohen ${ }^{4,9}$ and Benoit Schlemmer ${ }^{7}$

\begin{abstract}
Introduction: Several factors, including diuretic use and sepsis, interfere with the fractional excretion of sodium, which is used to distinguish transient from persistent acute kidney injury (AKI). These factors do not affect the fractional excretion of urea (FeUrea). However, there are conflicting data on the diagnostic accuracy of FeUrea.

Methods: We conducted an observational, prospective, multicenter study at three ICUs in university hospitals. Unselected patients, except those with obstructive AKI, were admitted to the participating ICUs during a six-month period. Transient AKI was defined as AKI caused by renal hypoperfusion and reversal within three days. The results are reported as medians (interquartile ranges).

Results: A total of 203 patients were included. According to our definitions, 67 had no AKI, 54 had transient AKI and 82 had persistent AKI. FeUrea was 39\% (28 to 40) in the no-AKI group, 41\% (29 to 54) in the transient AKI group and 32\% (22 to 51) in the persistent AKI group $(P=0.12$ ). FeUrea was of little help in distinguishing transient AKI from persistent AKI, with the area under the receiver operating characteristic curve being 0.59 (95\% confidence interval, 0.49 to $0.70 ; P=0.06$ ). Sensitivity was $63 \%$ and specificity was $54 \%$ with a cutoff of $35 \%$. In the subgroup of patients receiving diuretics, the results were similar.
\end{abstract}

Conclusions: FeUrea may be of little help in distinguishing transient AKI from persistent AKI in critically ill patients, including those receiving diuretic therapy. Additional studies are needed to evaluate alternative markers or strategies to differentiate transient from persistent AKI.

Keywords: acute kidney failure, ICU, fractional excretion of sodium, acute tubular necrosis, diuretics, sensitivity and specificity

\section{Introduction}

Acute kidney injury (AKI) is common and associated with high mortality in critically ill patients [1-3]. The causes of AKI other than urinary tract obstruction are usually divided into two categories: prerenal causes, in which low renal perfusion leads to promptly reversible renal dysfunction, and intrinsic causes with renal tissue damage and persistent renal dysfunction. Although pathological studies are lacking, the leading cause of

\footnotetext{
* Correspondence: michael.darmon@chu-st-etienne.fr

'Medical-Surgical Intensive Care Unit, Saint-Etienne University Hospital, and Jean Monnet University, Avenue Albert Raymond, F-42270 Saint-Etienne, France

Full list of author information is available at the end of the article
}

persistent AKI in critically ill patients is believed to be acute tubular necrosis (ATN) [4,5]. It is usually assumed that there is a continuum that leads from prerenal AKI to ATN [4-6]. Many publications in the fields of internal medicine, nephrology and critical care still advocate the use of urinary indices, such as the fractional excretion of sodium $(\mathrm{FeNa})$, to differentiate transient from persistent AKI [4,5,7-10]. However, diuretic therapy or sepsis may affect these indices [11-13]. Since urea reabsorption occurs mainly at the proximal segment of the nephron and is unaffected by diuretic intake, the fractional excretion of urea (FeUrea) may be more reliable than $\mathrm{FeNa}$ $[11,12,14]$. Studies evaluating the performance of FeUrea have produced discordant results $[11,12,14]$. In addition,
C Biomed Central

C 2011 Darmon et al.; licensee BioMed Central Ltd. This is an open access article distributed under the terms of the Creative Commons Attribution License (http://creativecommons.org/licenses/by/2.0), which permits unrestricted use, distribution, and reproduction in any medium, provided the original work is properly cited. 
no study specifically designed to evaluate FeUrea in critically ill patients has been conducted. A recent review underlined the lack of evidence supporting the use of usual urinary indices in critically ill patients and in patients with sepsis [15]. However, distinguishing transient AKI from persistent AKI can help the clinician to choose the optimal treatment for critically ill patients.

Our primary objective in this study was to evaluate the performance of FeUrea as a tool for distinguishing transient from persistent AKI in a cohort of critically ill patients. The secondary objectives were to evaluate the performance of the usual urinary indices in these patients and to evaluate the performance of the usual urinary indices and FeUrea in the subgroup of patients receiving diuretics.

\section{Materials and methods Patients}

The study was approved by the institutional review board of the French Society for Intensive Care Medicine (SRLF-CE-07-212), which waived the need for signed informed consent. Patients and their next of kin were informed, however, and none refused to participate. Three ICUs in university hospitals participated in the study between April and September 2008. Patients admitted to the participating ICUs were included, except those younger than 18 years of age, pregnant women, patients receiving dialysis for an underlying chronic kidney disease and patients with evidence of obstructive renal failure. Patients from whom urine could not be collected during the first six hours were excluded from this study.

\section{Protocol}

Each patient was assessed during the first 12 hours following ICU admission. Plasma sodium, urea and creatinine levels were measured at ICU admission, and urine was collected over the next six hours.

\section{Definitions}

AKI was defined according to the Acute Kidney Injury Network classification scheme [16] as a serum creatinine level increase of $26.4 \mu \mathrm{mol} / \mathrm{L}$ or more, a serum creatinine increase $\geq 150 \%$ from baseline or urine output $<$ $0.5 \mathrm{~mL} / \mathrm{kg} /$ hour for six hours or more. For patients whose baseline serum creatinine level was unknown, this variable was estimated using the Modification of Diet in Renal Disease (MDRD) formula [16,17].

Transient AKI was defined as AKI (of any stage) with a cause of renal hypoperfusion (that is, shock; dehydration; a medication interfering with renal perfusion, such as angiotensine-converting enzyme inhibitor; and so on) and recovery within three days. Recovery was defined as reversal of oliguria (in the absence of diuretics), and/or a $50 \%$ or greater decrease in serum creatinine [18], and/ or return of serum creatinine to the baseline value (whether measured or estimated using the MDRD formula $[16,17])$. Persistent AKI was defined as renal dysfunction without recovery within three days. Oliguria was defined as urine output $<0.5 \mathrm{~mL} / \mathrm{kg} /$ hour for six hours or more.

The FeNa percentage was calculated as ([urinary sodium/serum sodium]/[urinary creatinine/serum creatinine]) $\times 100$. The FeUrea percentage was calculated as ([urinary urea/serum urea]/[urinary creatinine/serum creatinine]) $\times 100$.

The Logistic Organ Dysfunction (LOD) score and the Simplified Acute Physiology Score version II (SAPS II) score were calculated at study inclusion $[19,20]$, and the Knaus scale score was determined to evaluate chronic health status at ICU admission (A: no limitation of activity, B: moderate limitation, C: severe limitation, and D: bedridden or institutionalized) [21]. Sepsis was diagnosed using the criteria developed by the American College of Chest Physicians/Society of Critical Care Medicine consensus conference [22]. Individual organ failure was defined as a LOD score greater than 1 point for each system except the kidney [19].

\section{Statistical analysis}

Patients remaining in the ICU for $<72$ hours were secondarily excluded from the analysis, since they could not be classified as having transient or persistent AKI according to our definition. The results are reported as medians and interquartile ranges (IQRs), numbers and percentages or as means \pm standard deviations (SD) to express the percentage changes. Categorical variables were compared using Fisher's exact test, and continuous variables were compared using the nonparametric Wilcoxon signed-rank test or the Mann-Whitney $U$ test for pairwise comparisons. The Friedman test was used to compare continuous variables across the three groups.

To determine how well FeUrea distinguished transient from persistent AKI (our primary objective), we plotted the receiver-operating characteristic (ROC) curves of the proportion of true positives against the proportion of false positives, depending on the prediction rule used to classify patients as having persistent AKI. A $2 \times 2$ table was established to determine the sensitivity and specificity of FeUrea in diagnosing persistent AKI. Cutoff values, defined as threshold values that maximized the sum of sensitivity and specificity, were determined on the ROC curves. The positive and negative likelihood (LH) ratios were computed. The same strategy was used to assess our secondary objectives, namely, the performance of the usual urinary indices in these patients and the performance of the usual urinary indices and of FeUrea in the subgroup of patients receiving diuretics. 
Last, to confirm the input of urinary indices to detect persistent AKI, we performed logistic regression analyses to identify variables significantly associated with persistent AKI measured by the estimated odds ratio (OR) with the $95 \%$ confidence interval $(95 \% \mathrm{CI})$. Variables yielding $P$ values $<0.20$ in the bivariate analyses were entered into a backward stepwise logistic regression model in which persistent AKI was the variable of interest. The covariates were entered into the model with critical entry and removal $P$ values of 0.2 and 0.1 , respectively. Last, since the performance of FeUrea was the primary objective of this study, this variable was forced into the final model. Colinearity and interactions were tested. The Hosmer-Lemeshow test was used to check the goodness of fit of the logistic regression.

All tests were two-sided, and $P$ values $<0.05$ were considered statistically significant. Statistical tests were performed using the SAS version 6.12 software package (SAS Institute, Cary, NC, USA).

\section{Results}

\section{Study population}

During the study period, 203 patients with a median age of 61 years (46 to 73) were included. Their main characteristics are reported in Table 1 . According to our definitions, 67 patients (33\%) had no AKI, 54 patients (26.6\%) had transient AKI and 82 patients (40.4\%) had persistent AKI.

At ICU admission, the median SAPS II score was 46 (34 to 60) and the median LOD score was 6 (4 to 9). Most patients were admitted for medical conditions (91.1\%). The main risk factors for AKI were sepsis (67.5\%), aminoglycoside therapy (20.7\%), chronic heart failure (19.8\%), chronic kidney disease (16.3\%) and exposure to iodinated contrast agents (8.9\%).

At the time of the study, no patient was being treated with renal replacement therapy (RRT). Forty-five patients required RRT during their ICU stay, usually during the first three days in the ICU ( 41 of 45 patients). Each of the patients requiring RRT during the first three days in the ICU had persistent AKI, whereas the remaining four patients had no AKI at ICU admission and required RRT later during their ICU stay.

\section{Diagnostic performance of FeUrea}

Median FeUrea was 37\% (26 to 49) overall, 39\% (28 to 40) in patients without AKI, 41\% (29 to 54) in patients with transient AKI and 32\% (22 to 51) in patients with persistent AKI $(P=0.12)$. Figures $1 \mathrm{a}, \mathrm{b}$ and $1 \mathrm{c}$ show the distributions of FeNa, FeUrea and urine/plasma (U/P) urea ratios, respectively, in each group.

The area under the ROC curve was 0.59 (95\% CI 0.49 to $0.70 ; P=0.06)$ (Figure 2). At the usual cutoff $(35 \%)$, FeUrea predicted persistent AKI with $63 \%$ sensitivity and $54 \%$ specificity (Table 2), yielding a positive LH of 1.37 and a negative $\mathrm{LH}$ of 0.68 . In the study population, the optimal cutoff was $37 \%$. However, the performance of FeUrea at this cutoff was poor (66\% sensitivity and $53 \%$ specificity) (Table 2).

\section{Diagnostic performance of other urinary indices}

The performance characteristics of classical urinary indices for detecting persistent AKI are reported in Table 2, with the usual and optimal cutoffs in the study population. Performance was best for the U/P urea ratio (ROC curve area under the curve (AUC) 0.71 (0.62 to $0.80)$ ) (Figure 2). A U/P urea ratio < 12 had $66 \%$ sensitivity and $66 \%$ specificity for persistent AKI (positive $\mathrm{LH}, 1.94$; negative $\mathrm{LH}, 0.52$ ). When entered into a regression logistic model, none of these urinary indices were independently associated with persistent AKI. Three variables were found to be associated with persistent AKI: chronic kidney disease (OR 11.89, 95\% CI 2.52 to $56.24 ; P=0.02$ ), need for vasopressors at ICU admission (OR 2.60, 95\% CI 1.15 to 5.91) and oliguria at ICU admission (OR 2.50, 95\% CI 1.11 to 5.63). The model had good calibration (goodness of fit $P=0.88$ ). FeUrea was then forced into the final model and was not selected.

\section{Diagnostic performance of urinary indices in patients undergoing diuretic therapy}

Overall, 67 patients (33\%) received diuretics before or at ICU admission. Among them, 17 had no AKI (25.4\% of patients without AKI), 18 had transient AKI (33.3\% of patients with transient AKI) and 32 had persistent AKI (39\% of patients with persistent AKI). The performance characteristics of urinary indices in patients undergoing diuretic therapy are reported in Table 2. As with the overall population, the performance of FeUrea in this patient subgroup was poor (ROC curve AUC 0.58 (0.41 to 0.75$))$. The $\mathrm{U} / \mathrm{P}$ urea ratio performed satisfactorily in differentiating transient from persistent AKI (ROC curve AUC 0.82 (0.70 to 0.94)). With a U/P urea ratio cutoff of 10 , sensitivity was $72 \%$, specificity was $69 \%$, positive LH was 2.32 and negative LH was 0.41 .

\section{Diagnostic performance of urinary indices in patients with sepsis at ICU admission}

Overall, 137 patients (67\%) had sepsis at ICU admission. Among them, 43 had no AKI (64.2\% of patients without AKI), 33 had transient AKI (61.1\% of patients with transient AKI) and 61 had persistent AKI (74.4\% of patients with persistent $\mathrm{AKI}$ ). The performance characteristics of urinary indices in patients with sepsis are reported in Table 2. As with the overall population, the performance of FeUrea in this patient subgroup was poor (ROC curve AUC 0.56 (0.43 to 0.68)). The performance of other 
Table 1 Characteristics of patients without AKI, with transient AKI and with persistent AKI ${ }^{\mathrm{a}}$

\begin{tabular}{|c|c|c|c|c|}
\hline Demographics & No AKI $(n=67)$ & Transient AKI $(n=54)$ & Persistent AKI $(n=82)$ & $P$ value $^{\mathrm{b}}$ \\
\hline \multicolumn{5}{|l|}{ Patient characteristics } \\
\hline Male gender & $34(50.7 \%)$ & $32(59.3 \%)$ & $56(68.3 \%)$ & 0.15 \\
\hline Age, years & 50 (40 to 60$)$ & 71 (49 to 76$)$ & 66 (56 to 74$)$ & $<0.0001$ \\
\hline Weight, kg & 68 (57 to 85$)$ & 75 (64 to 85$)$ & 80 (68 to 89$)$ & 0.006 \\
\hline Knaus score C or D [21] & $21(31.3 \%)$ & $21(38.9 \%)$ & $40(48.8 \%)$ & 0.09 \\
\hline LOD score at ICU admission [19] & $4(2$ to 7$)$ & $6(5$ to 9$)$ & 8 (5 to 9$)$ & $<0.0001$ \\
\hline SAPS II score at ICU admission [20] & 35 (27 to 47$)$ & 50 (39 to 62) & 52 (39 to 62) & $<0.0001$ \\
\hline \multicolumn{5}{|l|}{ Risk factors for AKI } \\
\hline Chronic heart failure & $8(11.9 \%)$ & $14(26.4 \%)$ & $18(22.0 \%)$ & 0.15 \\
\hline Chronic kidney disease ${ }^{c}$ & $1(1.5 \%)$ & $3(5.6 \%)$ & $23(28.0 \%)$ & $<0.0001$ \\
\hline Sepsis & $43(64.2 \%)$ & $33(61.1 \%)$ & $61(74.4 \%)$ & 0.12 \\
\hline Aminoglycosides & $8(11.9 \%)$ & $9(16.7 \%)$ & $25(30.5 \%)$ & 0.2 \\
\hline lonidated contrast agents & $6(9.0 \%)$ & $3(5.6 \%)$ & $9(11.0 \%)$ & 0.55 \\
\hline \multicolumn{5}{|l|}{ Organ failure at ICU admission } \\
\hline Medical condition & $62(92.5 \%)$ & $51(94.4 \%)$ & $72(87.8 \%)$ & 0.36 \\
\hline Acute respiratory failure & $54(80.6 \%)$ & $39(72.2 \%)$ & $61(74.4 \%)$ & 0.51 \\
\hline Coma & $22(32.8 \%)$ & $24(44.4 \%)$ & $29(35.4 \%)$ & 0.34 \\
\hline Shock & $22(32.8 \%)$ & $28(51.9 \%)$ & $43(52.4 \%)$ & 0.03 \\
\hline \multicolumn{5}{|l|}{ Treatments in the ICU } \\
\hline Need for vasoactive drugs & $20(29.9 \%)$ & $23(42.6 \%)$ & $43(52.4 \%)$ & 0.02 \\
\hline Mechanical ventilation & $43(64.2 \%)$ & $34(63.0 \%)$ & $52(63.4 \%)$ & 0.99 \\
\hline Noninvasive mechanical ventilation & $21(31.3 \%)$ & $14(25.9 \%)$ & $21(25.6 \%)$ & 0.73 \\
\hline Renal replacement therapy & $4(6.0 \%)$ & 0 & $41(50.0 \%)$ & $<0.0001$ \\
\hline Diuretics (at admission) & $17(25.4 \%)$ & $18(33.3 \%)$ & $32(39.0 \%)$ & 0.21 \\
\hline \multicolumn{5}{|l|}{ Renal function at admission } \\
\hline Diuresis, $\mathrm{mL} / \mathrm{kg} /$ hour $^{\mathrm{d}}$ & 0.69 (0.59 to 0.99$)$ & 0.45 (0.32 to 1.11$)$ & 0.40 (0.21 to 0.72$)$ & $<0.0001$ \\
\hline Plasma urea, $\mathrm{mmol} / \mathrm{L}$ & $5.4(3.4$ to 7.9$)$ & 13.1 (6.8 to 17.3$)$ & $17.4(10.9$ to 25.1$)$ & $<0.0001$ \\
\hline Serum creatinine, $\mu \mathrm{mol} / \mathrm{L}$ & 68 (59 to 78$)$ & $124(98$ to 164$)$ & 220 (138 to 360$)$ & $<0.0001$ \\
\hline \multicolumn{5}{|l|}{ Urinary indices } \\
\hline Urine $\mathrm{Na}^{+}$/urine $\mathrm{K}^{+}$ & $1.8(0.35$ to 1.75$)$ & $1.0(0.4$ to 1.8$)$ & 1.3 (0.5 to 2.4$)$ & 0.01 \\
\hline $\mathrm{FeNa}, \%$ & 0.5 (0.3 to 1.3$)$ & 0.5 (0.2 to 1.3$)$ & 0.8 (0.4 to 4.0$)$ & 0.004 \\
\hline FeUrea, \% & 39 (28 to 40 ) & 41 (29 to 54 ) & 32 (22 to 51$)$ & 0.12 \\
\hline U/P urea & 30 (19 to 39$)$ & 16 (9 to 25$)$ & 7 (4 to 14$)$ & $<0.0001$ \\
\hline U/P creatinine & 83 (52 to 127 ) & 47 (25 to 76 ) & 30 (11 to 58$)$ & $<0.0001$ \\
\hline \multicolumn{5}{|l|}{ Outcomes } \\
\hline ICU mortality & 7 (11.7\%) & 13 (25\%) & $37(48.1 \%)$ & 0.0002 \\
\hline Hospital mortality & 14 (20.9\%) & 15 (27.8\%) & $42(51.2 \%)$ & 0.0003 \\
\hline
\end{tabular}

${ }^{a}$ AKI: acute kidney injury; LOD: Logistic Organ Dysfunction score, which can range from 0 to 22; SAPS II: Simplified Acute Physiology Score version II; FeNa, fractional excretion of sodium ([urine sodium/serum sodium]/[urine creatinine/serum creatinine]) $\times 100$; FeUrea, fractional excretion of urea ([urine urea/serum urea]/[urine creatinine/serum creatinine]) $\times 100$; U/P urea, urine urea/plasma urea; U/P creatinine, urine creatinine/serum creatinine. Data are medians (IQR) or number of patients (\%). ${ }^{\mathrm{b}} \mathrm{P}$ values represent comparisons across the three patient groups. ${ }^{\mathrm{C} C h r o n i c}$ renal failure was defined as creatinine clearance $<60 \mathrm{~mL} /$ minute before ICU admission. ${ }^{d}$ Diuresis represents diuresis per kilogram and per hour during the first six hours following inclusion 


\section{(a)}

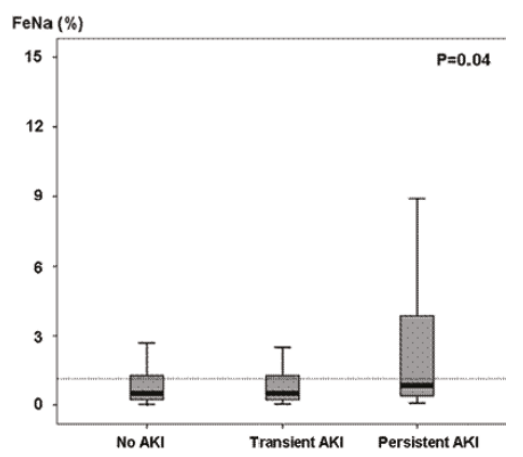

(b)

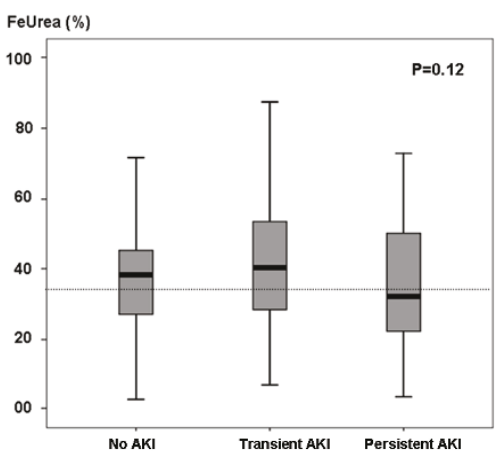

(c)

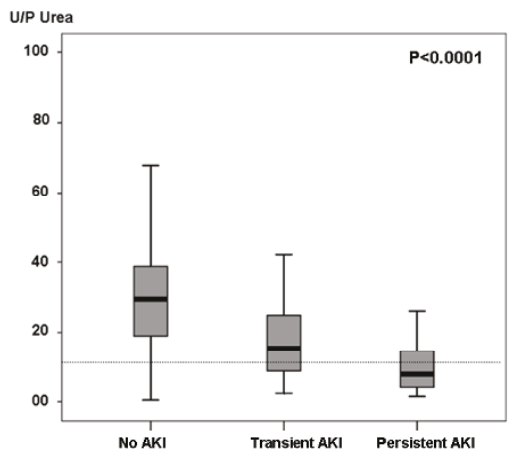

Figure 1 (a) Boxplot of the fractional excretion of sodium ( $\mathrm{FeNa}$ ) in the overall study population according to renal function. The dotted line represents FeNa of $1 \%(P=0.04)$. (b) Boxplot of the fractional excretion of urea (FeUrea) in the overall study population according to renal function. The dotted line represents FeUrea of $35 \%(P=0.12)$. (c) Boxplot of the urine/plasma (U/P) urea ratio in the overall study population according to renal function. The dotted line represents a U/P urea ratio of $10(P<0.0001)$.

\section{ROC Curve}

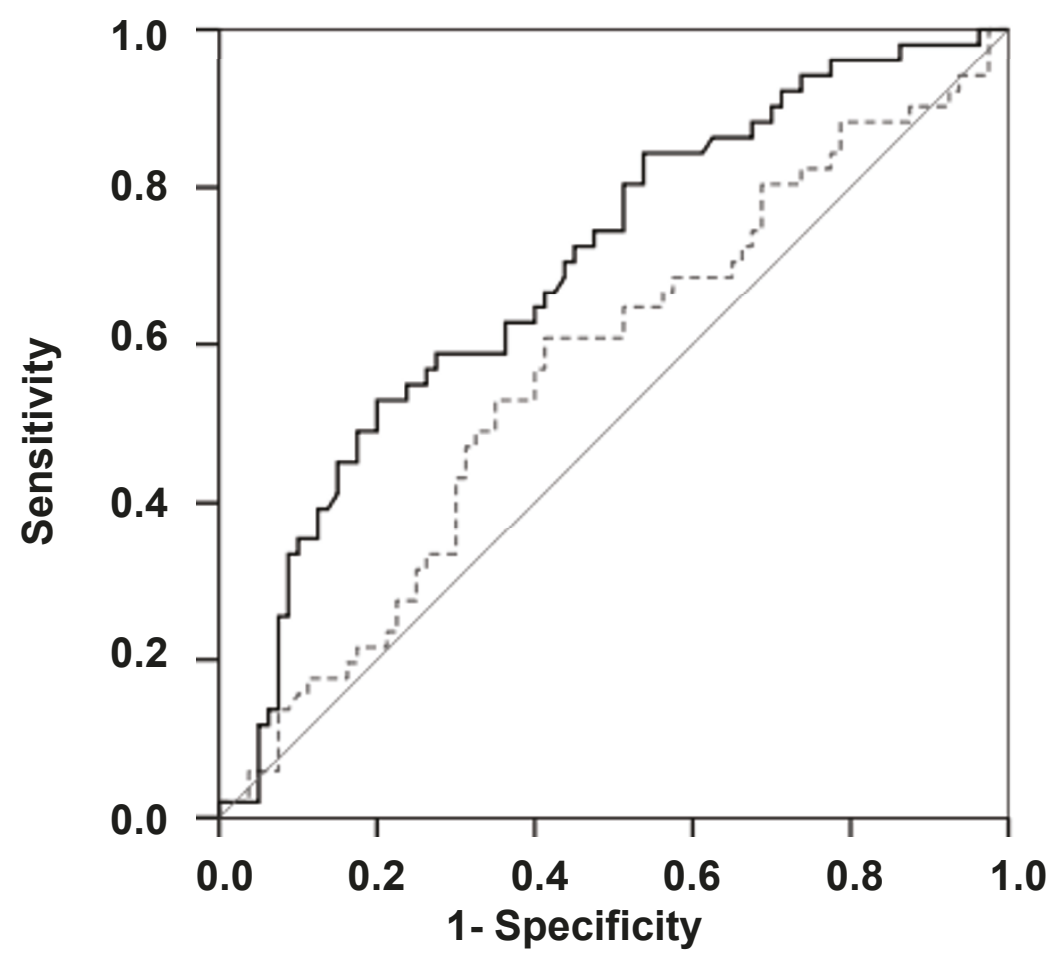

Source of the Curve -.---FeUrea U/P Urea - Reference line

\section{Diagonal segments are produced by ties.}

Figure 2 Receiver-operating characteristic (ROC) curve depicting the ability of the fractional excretion of urea (FeUrea) and urine/ plasma (U/P) urea ratio to detect persistent AKI in the subgroup of patients with AKI. The ROC curve shows the relationship between the proportion of true positives (Sensitivity) and the proportion of false positives (1-Specificity) with various FeUrea and U/P urea ratio cutoffs. Diagonal segments are produced by ties. The area under the ROC curve is 0.59 ( $95 \%$ confidence interval, 0.49 to $0.70 ; P=0.06$ ) for FeUrea. The area under the ROC curve is 0.71 (95\% confidence interval, 0.62 to $0.80 ; P=0.04$ ) for U/P urea ratio. 
Table 2 Performance of usual urinary markers for detecting patients with persistent AKI among patients with AKI, with the usual and optimal (*) cutoff values ${ }^{a}$

\begin{tabular}{|c|c|c|c|c|c|c|c|c|}
\hline Patient groups & $\begin{array}{l}\text { FeNa } \\
>1 \% \\
\end{array}$ & $\begin{array}{c}\mathrm{FeNa}^{*} \\
>0.58 \% \\
\end{array}$ & $\begin{array}{l}\text { FeUrea } \\
<35 \%\end{array}$ & $\begin{array}{c}\text { FeUrea* } \\
<37 \%\end{array}$ & $\begin{array}{c}\text { U/P urea } \\
<10\end{array}$ & U/P urea* $<12$ & $\mathrm{U} / \mathrm{P}$ creat $<20$ & $\mathrm{U} / \mathrm{P}$ creat $^{*}<12$ \\
\hline \multicolumn{9}{|c|}{ All patients with AKI $(n=136$; persistent AKI prevalence $=60.3 \%)$} \\
\hline Sensitivity (\%) & 0.48 & 0.63 & 0.63 & 0.66 & 0.74 & 0.66 & 0.79 & 0.59 \\
\hline Specificity (\%) & 0.7 & 0.61 & 0.54 & 0.53 & 0.57 & 0.66 & 0.39 & 0.59 \\
\hline Positive predictive value & 0.71 & 0.71 & 0.67 & 0.68 & 0.72 & 0.74 & 0.66 & 0.68 \\
\hline Negative predictive value & 0.47 & 0.47 & 0.47 & 0.51 & 0.59 & 0.56 & 0.55 & 0.48 \\
\hline Positive likelihood ratio & 1.6 & 1.61 & 1.37 & 1.4 & 1.72 & 1.94 & 1.3 & 1.44 \\
\hline Negative likelihood ratio & 0.74 & 0.61 & 0.68 & 0.64 & 0.45 & 0.52 & 0.54 & 0.69 \\
\hline Younden's index & 0.18 & 0.24 & 0.17 & 0.19 & 0.31 & 0.32 & 0.18 & 0.18 \\
\hline ROC AUC & \multicolumn{2}{|c|}{0.62 (0.52 to 0.72$)$} & \multicolumn{2}{|c|}{0.59 (0.49 to 0.70$)$} & \multicolumn{2}{|c|}{0.71 (0.62 to 0.80$)$} & \multicolumn{2}{|c|}{0.62 (0.53 to 0.72$)$} \\
\hline \multicolumn{9}{|c|}{ Patients taking diuretics $(n=50$; persistent AKI prevalence $=64 \%)$} \\
\hline Sensitivity (\%) & 0.75 & 0.62 & 0.61 & 0.61 & 0.72 & 0.61 & 0.78 & 0.89 \\
\hline Specificity (\%) & 0.56 & 0.56 & 0.47 & 0.59 & 0.69 & 0.75 & 0.5 & 0.38 \\
\hline Positive predictive value & 0.71 & 0.71 & 0.67 & 0.68 & 0.81 & 0.81 & 0.73 & 0.72 \\
\hline Negative predictive value & 0.47 & 0.47 & 0.49 & 0.51 & 0.58 & 0.52 & 0.56 & 0.66 \\
\hline Positive likelihood ratio & 1.7 & 1.41 & 1.15 & 1.49 & 2.32 & 2.44 & 1.56 & 1.44 \\
\hline Negative likelihood ratio & 0.47 & 0.68 & 0.83 & 0.66 & 0.41 & 0.52 & 0.44 & 0.29 \\
\hline Younden's index & 0.31 & 0.18 & 0.08 & 0.2 & 0.41 & 0.36 & 0.28 & 0.27 \\
\hline ROC AUC & \multicolumn{2}{|c|}{0.69 (0.54 to 0.81$)$} & \multicolumn{2}{|c|}{$0.58(0.41$ to 0.75$)$} & \multicolumn{2}{|c|}{$0.82(0.70$ to 0.94$)$} & \multicolumn{2}{|c|}{$0.71(0.56$ to 0.86$)$} \\
\hline \multicolumn{9}{|c|}{ Patients with sepsis ( $n=94$; persistent AKI prevalence $=65 \%$ ) } \\
\hline Sensitivity (\%) & 0.5 & 0.65 & 0.63 & 0.63 & 0.8 & 0.67 & 0.87 & 0.93 \\
\hline Specificity (\%) & 0.86 & 0.56 & 0.52 & 0.57 & 0.63 & 0.63 & 0.42 & 0.37 \\
\hline Positive predictive value & 0.87 & 0.73 & 0.71 & 0.73 & 0.8 & 0.63 & 0.74 & 0.73 \\
\hline Negative predictive value & 0.48 & 0.46 & 0.43 & 0.45 & 0.63 & 0.51 & 0.63 & 0.74 \\
\hline Positive likelihood ratio & 3.57 & 1.48 & 1.31 & 1.47 & 2.1 & 1.81 & 1.5 & 1.48 \\
\hline Negative likelihood ratio & 0.58 & 0.63 & 0.71 & 0.65 & 0.32 & 0.52 & 0.31 & 0.19 \\
\hline Younden's index & 0.36 & 0.19 & 0.15 & 0.2 & 0.43 & 0.3 & 0.29 & 0.3 \\
\hline ROC AUC & \multicolumn{2}{|c|}{0.67 (0.56 to 0.79$)$} & \multicolumn{2}{|c|}{0.56 (0.43 to 0.68$)$} & \multicolumn{2}{|c|}{0.71 (0.60 to 0.82$)$} & \multicolumn{2}{|c|}{0.65 (0.53 to 0.77$)$} \\
\hline
\end{tabular}

${ }^{\mathrm{a} A K I}$ : acute kidney injury; ROC: receiver operating characteristic; AUC: area under the curve.

urinary indices was similar to that in the overall patient population.

\section{Discussion}

In critically ill patients, FeUrea was not helpful in differentiating transient AKI from persistent AKI. Both in the overall population and in the subgroup of patients receiving diuretics, FeUrea performed less well than FeNa or the U/P urea ratio.

There is little scientific evidence to support the use of FeUrea. Only three studies have evaluated the accuracy of FeUrea in distinguishing transient from persistent AKI $[11,12,14]$. Their results are conflicting. In one study, FeUrea was $90 \%$ sensitive and $96 \%$ specific in differentiating transient from persistent AKI when a cutoff of $35 \%$ was used [11]. Conversely, another study found very poor diagnostic accuracy of FeUrea [12]. Several factors may explain these discordant results. First, these studies were single-center cohort studies and included only patients who were referred to nephrologists $[11,12]$.
In addition, the study populations were poorly described but include both critically ill patients and patients in wards. Therefore, selection bias and differences between the institutions and study populations may explain the discrepancies [11,12]. Furthermore, FeUrea reflects the ratio of urea clearance over creatinine clearance ratio. Variations in creatinine clearance may therefore modify FeUrea. In the study that found good performance of FeUrea $[11,12]$, wide differences in creatinine clearance can be suspected between patients with transient AKI and those with persistent AKI: serum creatinine levels were $140 \pm 22 \mu \mathrm{mol} / \mathrm{L}$ and $520 \pm 22 \mu \mathrm{mol} / \mathrm{L}$ (means $+/$ $\mathrm{SD})$ in these two groups, respectively.

Interestingly, the performance of urinary indices in our study was poor. Several factors may explain this finding. First, although many publications have advocated the use of urinary biochemistry indices to differentiate transient from persistent AKI, these indices have not been extensively studied in critically ill patients or in patients with sepsis $[4,5,23]$. The few published 
studies have had several limitations: most of them were single-center case series or retrospective studies, the definition of AKI varied across the studies and the definition of transient AKI also varied, being subjective in most instances [24-30]. Several of these studies included patients who did not have critical illnesses $[11,12,28]$. In addition, we chose a definition allowing for a distinction between transient and persistent AKI. Our study was therefore not designed to evaluate the interest of these indices in distinguishing prerenal and intrinsic AKI. This point may partly explain the poor performance of the urinary indices in our study. Last, most of the studied patients had sepsis or shock at ICU admission. This condition is frequently associated with renal handling of sodium or water independently of an underlying AKI. This may also explain the poor performance of these indices in the studied population. Nevertheless, taking these factors into account, and although the usual urinary indices were able to differentiate transient from persistent AKI, the accuracy of the indices was poor and none of them were independently associated with the diagnosis of persistent AKI, indicating a need to identify other biomarkers.

Our study has several limitations. First, our definition of transient AKI was mainly based on renal function recovery. Indeed, an accurate definition of prerenal AKI would have required a highly subjective definition based on clinical histories, physical examinations and physicians' judgments $[11,15]$. In addition, AKI is mainly due to sepsis in critically ill patients, and in this setting there is frequently a continuum between volume depletion and persistent kidney injuries rather than two distinct entities, with the two mechanisms being frequently associated. Therefore, we chose a definition that relies only on an objective criterion. This point needs to be taken into account to interpret our findings. In the same way, the course of kidney function may have been modified by factors following study inclusion. However, in the ICU setting, predicting which patients will have persistent AKI may help to optimize treatment, such as by promptly restoring renal perfusion, limiting fluids or starting RRT. Our definition was highly sensitive for detecting patients with transient AKI (none of the patients in this group required RRT) but lacked specificity, since only $50 \%$ of patients in the persistent AKI group required RRT. Additional studies may help to determine the definition that best matches the need for RRT.

Second, although renal function was assessed within a few hours after ICU admission, the time course of the urinary indices was not evaluated. FeNa is known to vary during the first 12 to 24 hours in critically ill patients $[13,30]$. Few data are available on the time course of other urinary indices [13]. Any variations might explain the poor performance of $\mathrm{FeNa}$ or the other urinary indices. Therefore, these variations need to be investigated to determine the optimal time for renal assessment in critically ill patients.

Last, few of our patients received diuretics. The poor performance of urinary indices in this subgroup may therefore be related to low statistical power.

\section{Conclusions}

In summary, we found that FeUrea and the usual urinary indices performed poorly in separating transient from persistent AKI in an unselected population of critically ill patients. Additional studies are needed to evaluate alternative markers of renal injury or strategies for differentiating transient from persistent AKI.

\section{Key messages}

- FeUrea performed poorly in separating transient from persistent AKI in critically ill patients.

- Although the usual urinary indices (FeNa, U/P urea ratio or U/P creatinine ratio) are able to differentiate transient from persistent AKI, their accuracy remains poor in this setting.

- The high incidence of situations that may induce renal handling of water or sodium (that is, sepsis or shock) may explain the poor performance of urinary indices in this setting.

- Additional studies are needed to evaluate alternative markers of renal injury or strategies for differentiating transient from persistent AKI.

\section{Abbreviations}

AKI: acute kidney injury; AUC: area under the curve; Cl: confidence interval; FeNa: fractional excretion of sodium; FeUrea: fractional excretion of urea; MV mechanical ventilation; OR: odds ratio; ROC: receiving operator characteristic; U/P creat: urine/serum creatinine ratio; U/P urea: urine/plasma urea ratio.

\section{Acknowledgements}

We thank A Wolfe, MD, for helping with this manuscript. Financial support consisted of a grant from the Assistance-Publique Hôpitaux de Paris (CRC 07 011), a nonprofit, government-funded organization.

\section{Author details}

${ }^{1}$ Medical-Surgical Intensive Care Unit, Saint-Etienne University Hospital, and Jean Monnet University, Avenue Albert Raymond, F-42270 Saint-Etienne, France. ${ }^{2}$ INSERM Unit 955, Paris-12 University, 51 Avenue du Marechal De Lattre de Tassigny, F-94010 Créteil, France. ${ }^{3}$ Thrombosis Research Group, EA 3065, Saint-Etienne University Hospital, and Saint-Etienne Medical School, Avenue Albert Raymond, F-42270 Saint-Etienne, France. ${ }^{4}$ Medical-Surgical Intensive Care Unit, Avicenne University Hospital, APHP, 125, rue de Stalingrad, F-93009 Bobigny, France. ${ }^{5}$ Medical Intensive Care Unit, Archet University Hospital, Nice, France; and Nice University, UFR de Médecine, 151 Rte Saint Antoine Ginestiere, F-06202 Nice, France. ${ }^{6}$ Medical Intensive Care Unit, AP-HP, Albert Chenevier-Henri Mondor University Hospital, and Paris-12 University, 51 Avenue du Marechal De Lattre de Tassigny, F-94010 Créteil, France. ${ }^{7}$ Medical ICU, Saint-Louis University Hospital, APHP, Avenue Claude Vellefaux, F-75010 Paris, France; and UFR de Médecine, Paris-7 Paris-Diderot University, Avenue Claude Vellefaux, F-75010 Paris, France. ${ }^{8}$ Medical-Surgical Intensive Care Unit, Hôpitaux Universitaires de Genève, 24, Micheli-du-Crest, CH-1211 Genève 14, Suisse. ${ }^{9}$ Paris-13 University, 125, rue de Stalingrad, F93009 Bobigny, France. 


\section{Authors' contributions}

MD had full access to all of the data in the study and takes responsibility for the integrity of the data and the accuracy of the data analysis. MD, FV and FS were responsible for the study concept and design. MD, FV, JD, FG and VD were responsible for the acquisition of data. MD, FV, FS, LB, GB, YC and $\mathrm{BS}$ analyzed and interpreted the data. MD and FV drafted the manuscript. Critical revision of the manuscript for important intellectual content: MD, FV, $J D, F S, F G, V D, F Z, L B, G B, Y C$ and $B S$ critically revised the manuscript for important intellectual content. MD carried out the statistical analysis. All authors approved the final version of the manuscript

\section{Competing interests}

The authors declare that they have no competing interests.

Received: 11 March 2011 Revised: 11 July 2011 Accepted: 27 July 2011 Published: 27 July 2011

\section{References}

1. Brivet FG, Kleinknecht DJ, Loirat P, Landais JP, French Study Group on Acute Renal Failure: Acute renal failure in intensive care units-causes, outcome, and prognostic factors of hospital mortality: a prospective, multicenter study. Crit Care Med 1996, 24:192-198.

2. Metnitz PG, Krenn CG, Steltzer H, Lang T, Ploder J, Lenz K, Le Gall JR, Druml W: Effect of acute renal failure requiring renal replacement therapy on outcome in critically ill patients. Crit Care Med 2002, 30:2051-2058

3. Uchino S, Kellum JA, Bellomo R, Doig GS, Morimatsu H, Morgera S, Schetz M, Tan I, Bouman C, Macedo E, Gibney N, Tolwani A, Ronco C, Beginning and Ending Supportive Therapy for the Kidney (BEST Kidney) Investigators: Acute renal failure in critically ill patients: a multinational, multicenter study. JAMA 2005, 294:813-818.

4. Lameire N, Van Biesen W, Vanholder R: Acute renal failure. Lancet 2005, 365:417-430

5. Schrier RW, Wang W: Acute renal failure and sepsis. N Engl I Med 2004, 351:159-169.

6. Lameire N, Biesen WW, Vanholder R: Acute kidney injury. Lancet 2008, 372:1863-1865.

7. Bock HA: Pathophysiology of acute renal failure in septic shock: from prerenal to renal failure. Kidney Int Suppl 1998, 64:S15-S18.

8. Espinel CH: The FENa test: use in the differential diagnosis of acute renal failure. JAMA 1976, 236:579-581.

9. Miller TR, Anderson RJ, Linas SL, Henrich WL, Berns AS, Gabow PA, Schrier RW: Urinary diagnostic indices in acute renal failure: a prospective study. Ann Intern Med 1978, 89:47-50.

10. Schrier RW, Wang W, Poole B, Mitra A: Acute renal failure: definitions, diagnosis, pathogenesis, and therapy. J Clin Invest 2004, 114:5-14.

11. Carvounis CP, Nisar S, Guro-Razuman S: Significance of the fractional excretion of urea in the differential diagnosis of acute renal failure. Kidney Int 2002, 62:2223-2229.

12. Pépin MN, Bouchard J, Legault L, Ethier J: Diagnostic performance of fractional excretion of urea and fractional excretion of sodium in the evaluations of patients with acute kidney injury with or without diuretic treatment. Am J Kidney Dis 2007, 50:566-573.

13. Van Biesen W, Yegenaga I, Vanholder R, Verbeke F, Hoste E, Colardyn F, Lameire $\mathrm{N}$ : Relationship between fluid status and its management on acute renal failure (ARF) in intensive care unit (ICU) patients with sepsis: a prospective analysis. J Nephrol 2005, 18:54-60.

14. Kaplan AA, Kohn OF: Fractional excretion of urea as a guide to renal dysfunction. Am J Nephrol 1992, 12:49-54.

15. Bagshaw SM, Langenberg C, Bellomo R: Urinary biochemistry and microscopy in septic acute renal failure: a systematic review. Am J Kidney Dis 2006, 48:695-705.

16. Mehta RL, Kellum JA, Shah SV, Molitoris BA, Ronco C, Warnock DG, Levin A, Acute Kidney Injury Network: Acute Kidney Injury Network: report of an initiative to improve outcomes in acute kidney injury. Crit Care 2007, 11: R31.

17. Bellomo R, Ronco C, Kellum JA, Mehta RL, Palevsky P, Acute Dialysis Quality Initiative workgroup: Acute renal failure-definition, outcome measures, animal models, fluid therapy and information technology needs: the Second International Consensus Conference of the Acute Dialysis Quality Initiative (ADQI) Group. Crit Care 2004, 8:R204-R212.
18. Schortgen F, Lacherade JC, Bruneel F, Cattaneo I, Hemery F, Lemaire F, Brochard L: Effects of hydroxyethylstarch and gelatin on renal function in severe sepsis: a multicentre randomised study. Lancet 2001, 357:911-916.

19. Le Gall JR, Klar J, Lemeshow S, Saulnier F, Alberti C, Artigas A, Teres D: The Logistic Organ Dysfunction system. A new way to assess organ dysfunction in the intensive care unit. ICU Scoring Group. JAMA 1996, 276:802-810

20. Le Gall JR, Lemeshow S, Saulnier F: A new Simplified Acute Physiology Score (SAPS II) based on a European/North American multicenter study. JAMA 1993, 270:2957-2963.

21. Knaus WA, Zimmerman JE, Wagner DP, Draper EA, Lawrence DE: APACHEacute physiology and chronic health evaluation: a physiologically based classification system. Crit Care Med 1981, 9:591-597.

22. Levy MM, Fink MP, Marshall JC, Abraham E, Angus D, Cook D, Cohen J, Opal SM, Vincent JL, Ramsay G, SCCM/ESICM/ACCP/ATS/SIS: 2001 SCCM/ ESICM/ACCP/ATS/SIS International Sepsis Definitions Conference. Crit Care Med 2003, 31:1250-1256.

23. Bagshaw SM, Laupland KB, Doig CJ, Mortis G, Fick GH, Mucenski M, Godinez-Luna T, Svenson LW, Rosenal T: Prognosis for long-term survival and renal recovery in critically ill patients with severe acute renal failure: a population-based study. Crit Care 2005, 9:R700-R709.

24. Diamond JR, Yoburn DC: Nonoliguric acute renal failure associated with a low fractional excretion of sodium. Ann Intern Med 1982, 96:597-600.

25. du Cheyron D, Daubin C, Poggioli J, Ramakers M, Houillier P, Charbonneau P, Paillard M: Urinary measurement of $\mathrm{Na}^{+} / \mathrm{H}^{+}$exchanger isoform 3 (NHE3) protein as anew marker of tubule injury in critically ill patients with ARF. Am J Kidney Dis 2003, 42:497-506.

26. Hilton PJ, Jones NF, Barraclough MA, Lloyd-Davies RW: Urinary osmolality in acute renal failure due to glomerulonephritis. Lancet 1969, 2:655-656.

27. Lam M, Kaufman CE: Fractional excretion of sodium as a guide to volume depletion during recovery from acute renal failure. Am J Kidney Dis 1985, 6:18-21.

28. Tungsanga K, Boonwichit D, Lekhakula A, Sitprija V: Urine uric acid and urine creatinine ratio in acute renal failure. Arch Intern Med 1984, 144:934-937.

29. Werb R, Linton AL: Aetiology, diagnosis, treatment and prognosis of acute renal failure in an intensive care unit. Resuscitation 1979, 7:95-100.

30. Westhuyzen J, Endre ZH, Reece G, Reith DM, Saltissi D, Morgan TJ: Measurement of tubular enzymuria facilitates early detection of acute renal impairment in the intensive care unit. Nephrol Dial Transplant 2003, 18:543-551.

doi:10.1186/cc10327

Cite this article as: Darmon et al: Diagnostic performance of fractional excretion of urea in the evaluation of critically ill patients with acute kidney injury: a multicenter cohort study. Critical Care 2011 15:R178.

\section{Submit your next manuscript to BioMed Central and take full advantage of:}

- Convenient online submission

- Thorough peer review

- No space constraints or color figure charges

- Immediate publication on acceptance

- Inclusion in PubMed, CAS, Scopus and Google Scholar

- Research which is freely available for redistribution

Submit your manuscript at www.biomedcentral.com/submit
Ciomed Central 